\title{
Management of parapneumonic effusion and empyema
}

\author{
T N Hilliard, A J Henderson, S C Langton Hewer
}

Arch Dis Child 2003;88:915-917

See end of article for authors' affiliations

......

Correspondence to: Dr S C Langton Hewer, Department of Respiratory

Medicine, Bristol Royal

Hospital for Children,

Upper Maudlin Street,

Bristol Children's Hospital,

Bristol BS2 8BJ, UK;

simon.langtonhewer@

bristol.ac.uk

Accepted

24 December 2002
Aims: To gather data on the clinical presentation of parapneumonic effusion and empyema and to examine the effect of different management strategies on short term outcomes.

Methods: Retrospective case note review of 48 children admitted to a tertiary unit between January 1998 and March 2001. Effusions were classified into three stages dependent on ultrasound findings. Results: The stage of effusion was not associated with duration of previous symptoms or length of previous admission. An interventional procedure was performed on median day 2 of admission in 46 children: eight $(17 \%)$ had an intercostal drain alone, $14(29 \%)$ had an intercostal drain followed by intrapleural fibrinolytic therapy, and $24(50 \%)$ had a thoracotomy. Three children who had an initial intercostal drain alone returned to theatre for thoracotomy, and two children who had intrapleural fibrinolysis returned for thoracotomy. Median length of stay (interquartile range) for each initial procedure was 15 days (6-20) for intercostal drain alone, 8 days (6-12) for fibrinolytic therapy, and 6.5 days (5-9) for thoracotomy. Stay for intercostal drain alone was significantly longer than for thoracotomy. Conclusion: Early surgical management of empyema is associated with a favourable outcome.
$\mathrm{T}$ he optimal management of parapneumonic effusions and empyema in children remains controversial and currently there is insufficient evidence to give clear guidance on therapy. Strategies include a conservative approach with antibiotic therapy, the use of chest drains, intrapleural fibrinolytic therapy, video assisted thoracoscopic therapy (VATS), and more aggressive surgical intervention with thoracotomy and decortication. To further complicate matters, parapneumonic effusion and empyema are unlikely to be a single entity, and more probably lie on an evolving continuum. ${ }^{12}$ Children therefore need to be treated differently depending on their clinical picture. Retrospective reviews have contributed to our knowledge of the disease processes and treatment, but these have often been over relatively long time periods with the use of evolving surgical strategies and imaging techniques. ${ }^{3-6}$ More recently there has been a trend for the use of fibrinolytic therapy and less invasive surgery, and a move away from thoracotomy. We reviewed our experience with a large number of children with parapneumonic effusion and empyema over a short time interval. Our aims were to gather data on clinical presentation and to examine the effect of different management strategies on short term outcomes.

\section{METHODS}

We performed a retrospective case note review of children admitted with parapneumonic effusion or empyema to our hospital between January 1998 and March 2001. Cases were selected by searching coded discharge records for the terms pleural effusion, empyema, and parapneumonic effusion. Cases of pleural effusion which were not due to infection were excluded. Information on referral pattern, preceding symptoms, blood and microbiological investigations, treatment, and duration of admission was entered by $\mathrm{TH}$ onto a paper proforma. This was then transferred to a Microsoft Access database (Access 2000, 9.0, Microsoft, WA, USA).

Classification of ultrasound appearances was performed retrospectively from the written report in the case notes, using a previously published staging system. ${ }^{7}$ Stage 1 refers to anechogenic collections without loculations; stage 2 has fibrinous septation but no homogeneous echogenic loculations or thickened parietal rind; and stage 3 has a complex ultrasound appearance with a thickened rind, multiple loculations, and entrapped underlying lung. Decisions regarding treatment were taken by the clinicians involved with that patient according to referral $\mathrm{AJH}, \mathrm{SLH}$, or one of the paediatric surgeons).

Patients were divided into groups depending on the initial therapeutic procedure and whether they had intrapleural fibrinolytic therapy, as follows: ( 1 ) chest drain alone; (2) chest drain and intrapleural fibrinolytic therapy; and (3) thoracotomy. Analysis of non-parametric data was performed with the Mann-Whitney U test comparing medians using GB-STAT version 7.0 statistical software (Dynamic Microsystems Inc., Silver Spring, MD, USA).

\section{RESULTS}

Forty nine patients were admitted during the three year study period and 48 case notes were available for review. The median (range) age was 5.16 years ( 18 days to 15.16 years). Twenty three were male $(48 \%)$. Forty one patients $(85 \%)$ were admitted from other paediatric inpatient units in the region. The admissions were evenly distributed over the three years studied, with the most common months of admission being December and February. Twenty three children had right sided involvement $(48 \%)$, and one had bilateral parapneumonic effusions (2\%). One child had Down's syndrome, one had acute lymphoblastic leukaemia, and one child was later diagnosed as having common variable immunodeficiency. Seven children had pre-existing asthma (15\%).

The median duration of preceding symptoms before first hospital admission was 9 days (range 1-39 days). The most common symptom was cough (73\%). Chest pain was present in $16(33 \%)$ and abdominal pain in five patients $(10 \%)$. Median (range) duration of preceding admission was 3 days (0-34 days).

The results of blood investigations were documented in 45 of the 48 patients studied (94\%). Initial blood tests showed significant anaemia $(\mathrm{Hb}<100 \mathrm{~g} / \mathrm{l})$ in $27 \%$, leucocytosis (white cell count $>13000$ per $\mathrm{mm}^{3}$ ) in $83 \%$, leucopenia (white cell count $<2000$ cells per $\mathrm{mm}^{3}$ ) in $3 \%$, and hyponatraemia (serum sodium less than $133 \mathrm{mmol} / \mathrm{l}$ ) in $42 \%$. Thrombocytosis (platelets greater than 500000 per $\mathrm{mm}^{3}$ ) was seen in $79 \%$ at some stage during their admission, with 13\% having a platelet count greater than 1000000 per $\mathrm{mm}^{3}$. Diagnostic pleurocentesis was performed in eight children (17\%). 
Table 1 Stage of effusion and initial therapeutic procedure performed

\begin{tabular}{llllc}
\hline Stage & $\begin{array}{l}\text { No } \\
\text { procedure }\end{array}$ & ICD & $\begin{array}{l}\text { ICD and } \\
\text { fibrinolysis }\end{array}$ & Thoracotomy \\
\hline 1 & 0 & 2 & 3 & 1 \\
2 & 2 & 5 & 5 & 6 \\
3 & 0 & 0 & 6 & 16 \\
Unclear & & 1 & & 1 \\
\hline
\end{tabular}

$I C D$, intercostal drain

All children had chest radiographs performed and all were abnormal. Chest ultrasound was performed in 46 children (96\%). Twenty seven children had chest ultrasound performed at their local hospital, and 19 had this repeated at our unit. If ultrasound had been performed twice, our ultrasound report was used for staging. A stage 1 effusion was seen in $12 \%$, a stage 2 effusion in $38 \%$, and a stage 3 complex empyema in $46 \%$. Loculi were seen in $65 \%$. In two children (4\%) the result of the ultrasound was not sufficiently clear to allow staging. Computed tomography was performed in three children (6\%). Stage of effusion was not associated with duration of previous symptoms or the length of the previous admission.

An intercostal drain had been inserted in three children at their local hospital but removed before admission. A therapeutic procedure was performed in 46 children (96\%) on median day 2 of the admission (range: day 1 to day 8). An intercostal drain alone was placed in $22(46 \%)$, and a thoracotomy was performed in 24 children (50\%). A formal decortication was performed in eight ( $17 \%)$. One child had a small pigtail type intercostal drain.

Intrapleural fibrinolytic therapy was used in 15 children $(31 \%)$, in association with an intercostal drain in 14 and in one after a thoracotomy. Urokinase 40000 units was diluted in 40 $\mathrm{ml}$ of saline and given via the chest drain every 12 hours for a median of 3 days (range 1-5 days). Eight children had an intercostal drain but did not have fibrinolytic therapy. Table 1 shows the therapeutic procedures categorised by the stage of the effusion.

Three of eight (38\%) children returned to theatre for a thoracotomy for failure of therapy after an initial intercostal drain alone, and two of $14(14 \%)$ returned after an intercostal drain with fibrinolytic therapy. Four children returned to theatre for a further intercostal drain due to drain displacement, blockage or pneumothorax. Intercostal drains remained in place for a median of 4 days (range 2-12 days).

Cultures were positive in two of the eight pleurocenteses performed before a therapeutic procedure. There was a significant growth of organisms from the following sources: blood in seven children (15\%), pleural fluid at the time of drain insertion in seven (15\%), and sputum in two $(4 \%)$. Serology was diagnostic in two children $(4 \%)$. Overall, organisms were identified in 15 children (31\%), as shown in table 2 .

Table 2 Organisms identified from pleural fluid, blood, or sputum

\begin{tabular}{lc}
\hline Organism & No. of children \\
\hline Streptococcus pneumoniae & 4 \\
Group A Streptococcus & 2 \\
Staphylococcus aureus & 3 \\
Coagulase negative Staphylococcus spp. & 3 \\
Coliforms & 1 \\
Gram negative bacilli & 1 \\
Mycoplasma pneumoniae (on serology) & 1 \\
No organism identified & 33 \\
\hline
\end{tabular}

Table 3 Length of stay and stay after surgery categorised by initial interventional procedure

\begin{tabular}{|c|c|c|c|}
\hline $\begin{array}{l}\text { Initial surgical } \\
\text { procedure }\end{array}$ & $\mathrm{n}$ & $\begin{array}{l}\text { Median length } \\
\text { of stay (days) } \\
\text { (IQR) }\end{array}$ & $\begin{array}{l}\text { Median stay } \\
\text { after procedure } \\
\text { (days) (IQR) }\end{array}$ \\
\hline Medical therapy alone & 2 & 3 & \\
\hline ICD only & 8 & $(6-20) \dagger$ & $13 \quad(5-19) \ddagger$ \\
\hline ICD and fibrinolytic therapy & 14 & $8 \quad(6-12)$ & $7.5(6-10)$ \\
\hline Thoracotomy & 22 & $6.5(5-9)$ & $6 \quad(5-7)$ \\
\hline
\end{tabular}

$I C D$, intercostal drain; $I Q R$, interquartile range.

$\dagger p=0.033$ for ICD $v$ thoracotomy. $\ddagger p=0.024$ for ICD $v$ thoracotomy

Streptococcus pneumoniae was the most common organism isolated (in four children, $8 \%$ ). Antibiotics were used intravenously in our unit for a median of 6 days (range 1-23 days), and oral antibiotics for a median of 21 days (range 0-64 days). The median number of different antibiotics in individual patients was 3 (range $1-5$ ).

The median length of stay was 7 days (range 1-59, interquartile range 6-11). Stay in hospital after the first procedure was a median of 6 days (range 3-51 days, interquartile range 5-10 days). Table 3 shows duration of admission categorised by the first procedure. Duration of admission and stay after surgery was significantly shorter for those children who had an initial thoracotomy compared to those who an initial intercostal drain only. Stay following fibrinolytic therapy appeared to be shorter than with an intercostal drain alone, but this was not statistically significant $(p=0.16)$. Length of stay was not associated with the initial ultrasound appearance, with the length of stay for each stage as follows: stage 1, median 6 days (range 5-13); stage 2, median 7.5 days (range 1-22); stage 3, median 7 days (range 3-59).

\section{DISCUSSION}

This study provides a retrospective review of the management of a large group of children with parapneumonic effusion or empyema in a tertiary centre in the United Kingdom over a short time interval. It shows a reduction in the length of stay in hospital compared to previous retrospective reviews..$^{4-6}$ Children who had a thoracotomy as an initial procedure recovered quickly and had the shortest length of stay. Intrapleural fibrinolysis was used in $31 \%$ of children and this group also appeared to do well.

The strengths of this study lie in its short time interval during which there were no major changes in surgical strategy or imaging techniques. It is however not a randomised trial of different surgical techniques, and therefore one must place limits on the strength of evidence that can be obtained, especially with regard to short term outcomes. The patients studied were a heterogeneous group, with a wide range in duration of preceding symptoms and prior admission. It is important not to over-extrapolate these results into a treatment strategy for an individual. However, these patients probably best represent the more severe end of the spectrum of parapneumonic pleural inflammation, as these were mostly referrals from other hospitals in the area. Patients with small simple effusions were probably not referred. Almost half (48\%) had complicated empyemas on ultrasound evaluation, and only $12 \%$ were (retrospectively) classified as simple effusions. In addition all but two children had some form of interventional procedure. We also accept that we have not evaluated long term outcome. We considered that this would not be feasible in a retrospective study, and much of the follow up occurred in the local hospital rather than at our centre. Data on lung function, radiological resolution, and cosmetic appearance would be valuable in evaluating long term implications of each strategy.

We used ultrasound as our main imaging technique to guide therapy. This is in contrast to some other surveys that 
have advocated chest computed tomography (CT) as the next imaging modality after chest radiographs. ${ }^{45}$ In fact, in one series the mean number of CT scans per patient was 2.7. Ultrasound in experienced hands can show the presence of septations, loculations, thickened pleura, and the mobility of the underlying lung. ${ }^{8}$ We avoided CT in all but three children, avoiding cost, radiation burden, and potentially the need for further anaesthesia.

Organisms were identified in $31 \%$ of children, which is low but similar to previous surveys. ${ }^{3}$ The most common organism was Streptococcus pneumoniae, but $20 \%$ of organisms were Staphylococcus aureus, underlying the need for antistaphyloccocal cover. Only $17 \%$ of cases had prior aspiration of the pleural effusion, and more widespread adoption of early aspiration may aid organism identification. More recent techniques of antigen detection with polymerase chain reaction can increase the diagnostic yield further.' We found that thrombocytosis was common, which has been previously described ${ }^{4}$ but the degree of thrombocytosis was particularly high (greater than 1000) in $13 \%$ at some stage of the admission. One child had a significant immunodeficiency diagnosed following his presentation with empyema, and this highlights the importance of further investigation of immune function in some patients, particularly those with repeated significant infections or a family history of immune deficiency.

Properties of pleural fluid such as glucose, lactate dehydrogenase, and $\mathrm{pH}$ have been proposed as a guide to dictating treatment in adults, ${ }^{1}$ but these have not been adequately evaluated in children. In a series of 85 adults with pleural infection, only the absence of purulence of pleural fluid was found to be a useful predictor of success of chest drainage and intrapleural fibrinolysis. ${ }^{10}$ We found that the duration of preceding symptoms or previous admission was unrelated to the stage of the effusion, which suggests that the rate of progression of pleural inflammation varies between individuals and the organism responsible.

The median length of stay for the whole group was short compared with other surveys. ${ }^{4-6}$ There was a clear statistical and clinical difference in the length of stay between those children who had an initial thoracotomy (median 6.5 days) and those who had only a chest drain inserted (median 15 days). Those children who had chest drains alone tended to be those with less complex effusions (table 1), compared to those who had thoracotomies. One might expect that the former might recover more quickly than those children who had more major surgery. This was clearly not the case with discharge at a median of 6 days after thoracotomy. Rapid recovery after thoracotomy has also been shown in recent smaller series with an aggressive surgical approach to complex empyema. ${ }^{7}$ Of the eight children who had an intercostal chest drain alone, three $(38 \%)$ returned to theatre for a thoracotomy. This outcome significantly prolongs length of stay and involves a second anaesthetic.

Intrapleural fibrinolytic therapy was used in $31 \%$ of patients and in all three ultrasound assessed stages. Median length of stay at 8 days was similar to the thoracotomy group and appeared shorter than the intercostal chest drain alone group, although this was not statistically significant for the small numbers involved. There have been several small case series of the use of fibrinolysis in paediatric empyema, and there has been a recent randomised placebo controlled trial of urokinase. ${ }^{11}$ This reported a 2 day reduction in hospital stay in those children given urokinase (to 7.4 days), with a further reduction if a small percutaneous drain was used. Only five of the 58 children in the trial required thoracotomy, which is a much lower proportion than in our study. The children in this trial may therefore represent a different part of the spectrum of severity, with only $7 \%$ having densely echogenic collections and $40 \%$ loculations on ultrasound.

Several retrospective series evaluating the use of video assisted thoracoscopic surgery (VATS) have shown that it is a safe and effective therapy in children, even with advanced disease. ${ }^{5-15}$ It appears to be associated with short lengths of stay, and some centres propose it as a primary procedure $e^{12-15}$ in loculated effusions. However, some children still require thoracotomy after a VATS procedure, and some groups accept its limitations compared to thoracotomy ${ }^{16}{ }^{17}$ For those children who have dense collections and a thickened pleural rind, the ability of either fibrinolytic therapy or VATS to provide clearance of the pleural space must be questioned. In these advanced empyemas our surgeons prefer to perform a thoracotomy with debridement of the pleural space. This study suggests that this approach provides rapid recovery, with little risk of a second surgical procedure being required.

\section{Conclusions}

This retrospective review gives an overview of current management of parapneumonic effusion and empyema in a single institution in the United Kingdom. Children who had a thoracotomy recovered quickly and had a better outcome than those who initially had a chest drain alone. This observation supports early and aggressive management of complicated effusions. Those who had fibrinolytic therapy also had a favourable outcome and there is now evidence of its efficacy in children. We believe that a randomised trial is now required to compare the therapeutic options available, including fibrinolysis and VATS

\section{ACKNOWLEDGEMENTS}

We would like to thank Chrissie Gardner for her advice in setting up the study and help in extracting case notes; Dr Sue King for advice regarding staging the ultrasound examinations; and the paediatric surgeons for their advice regarding the study and permission to use the case notes of their patients.

\section{Authors' affiliations \\ T N Hilliard, A J Henderson, S C Langton Hewer, Bristol Royal} Hospital for Children, UK

\section{REFERENCES}

1 Light RW. A new classification of parapneumonic effusions and empyema. Chest 1995;108:299-301.

2 Kroegel C, Antony VB. Immunobiology of pleural inflammation: potential implications for pathogenesis, diagnosis and therapy. Eur Respir J 1997; 10:2411-18.

3 Shankar KR, Kenny SE, Okoye BO, et al. Evolving experience in the management of empyema thoracis. Acta Paediatr 2000;89:417-20.

4 Chan PWK, Crawford O, Wallis C, et al. Treatment of pleural empyema. J Paediatr Child Health 2000;36:375-7.

5 Meier AH, Smith B, Raghavan A, et al. Rational treatment of empyema in children. Arch Surg 2000;135:907-12.

6 Chan W, Keyser-Gauvin E, Davis GM, et al. Empyema thoracis in children: a 26 year review of the Montreal Children's Hospital experience. J Pediatr Surg 1997:32:870-2.

7 Carey JA, Hamilton JRL, Spencer DA, et al. Empyema thoracis: a role for open thoracotomy and decortication. Arch Dis Child 1998;79:510-13.

8 King S, Thomson A. Radiological perspectives in empyema. Br Med Bull 2002;61:203-14.

9 Vuori-Holopainen E, Salo E, Saxen H, et al. Etiological diagnosis of childhood pneumonia by use of transthoracic needle aspiration and modern microbiological methods. Clin Infect Dis 2002;34:583-90.

10 Davies CWH, Kearney SE, Gleeson FV, et al. Predictors of outcome and long-term survival in patients with pleural infection. Am J Respir Crit Care Med 1999:160:1682-7.

11 Thomson AH, Hull J, Kumar MR, et al. Randomised trial of intrapleural urokinase in the treatment of childhood empyema. Thorax 2002;57:343-7. 12 Grewal H, Jackson RJ, Wagner CW, et al. Early video-assisted thoracic surgery in the management of empyema. Pediatrics 1999;103:e63.

3 Gandhi RR, Stringel G. Video-assisted thoracoscopic surgery in the management of pediatric empyema. JSLS 1997;1:251-3.

14 Doski JJ, Lou D, Hicks BA, et al. Management of parapneumonic collections in infants and children. J Pediatr Surg 2000;35:265-70.

15 Subramaniam R, Joseph VT, Tan GM, et al. Experience with video-assisted thoracoscopic surgery in the management of complicated pneumonia in children. J Pediatr Surg 2001;36:316-19.

16 Steinbrecher HA, Najmaldin AS. Thoracoscopy for empyema in children. J Pediatr Surg 1998;33:708-10.

17 Tonz M, Ris HB, Kaiser G. Is there a place for thoracoscopic debridement in the treatment of empyema in children? Eur J Pediatr Surg 2000;10:88-91. 